\title{
English Communication Skills: How Are They Taught at Schools and Universities in Oman?
}

\author{
Rahma Al-Mahrooqi \\ Sultan Qaboos University, Oman \\ PO box 42, Postal Code 123, Muscat \\ Tel: 968-9985-0800Ｅ-mail:mrahma@squ.edu.om
}

Received: January 2, 2012

doi:10.5539/elt.v5n4p124
Accepted: January 26, 2012

Published: April 1, 2012

\begin{abstract}
The aim of this paper is to investigate, from a student perspective, how English communication skills are taught in Oman's schools and higher education institutions. Previous research has documented the lack of communicative ability in English among school and higher education graduates in Oman (Al-Issa, 2007; Moody, 2009). However, the reasons for this weakness have never been investigated from the point of view of students themselves. Using written protocols from 58 respondents, this study embarks on such an investigation and explores student definitions of communication skills, opinions about their importance, and how they were taught in school and higher education institutions. The results reveal that these crucial skills were actually either not taught at all or taught indirectly, which helps to explain the deficit under investigation.
\end{abstract}

Keywords: English communication skills, Public schools, Higher education, Oman

\section{Introduction}

When responding to the Arab Spring that started in early 2011, caused by such factors as poverty and unemployment, it is important for Arab states to review their educational policies, especially at the tertiary levels of education. In the words of Mazawi (2010):

Debates and controversies continue to rage over the role of higher education institutions in effecting social, political, and economic transformations that would successfully leverage reform efforts undertaken in various parts of the Arab region. (p. 41)

Hence, important questions must be asked. For example, what does the job market require? Are tertiary education institutions preparing graduates with skills that match job market requirements? To effectively curb uprisings and dissatisfaction in the Arab world, education has to prepare capable cadres who possess the skill sets required by the job market. Current educational systems have failed to do this, which has led to the employment of expatriates instead of nationals (Al-Shaqsi, 2012; Issan \& Gomaa, 2010). One of the most important skills that education in the Arab Gulf has failed to equip their graduates with is a communicative ability in English (Moody, 2009; Al-Issa, 2011). Research and experience have proved that the majority of school and college graduates possess neither adequate English language skills nor communication skills to function effectively in the workplace, which is dominated by expatriates from around the world. Since a communicative ability in English is vital for success in higher studies as well as in the job market, it is essential that Arab countries revise their educational policies to bring about reform and positive change.

\section{English, Employability and Communication}

Globalization and the dominance of the United States in the $20^{\text {th }}$ (Friedman, 2009) and $21^{\text {st }}$ centuries have led to the global spread of English (Crystal, 2003) as the international language of communication, science, technology, medicine, tourism, and many other fields (Altbach, 2010; Graddol, 2006; Crystal, 1992; Phillipson, 1992; Bisong, 1995). Nowadays,

English functions as a bridge that synchronically and diachronically connects students as individuals with an enormous knowledge base and resource of information. The amount of information stored in English is huge, but it is not readily accessible to those who do not know the language. (Tuzlukova and Al-Mahrooqi, 2010, p. 41)

Because English is undisputedly the language of information and technology, it is expected to remain influential in the coming few decades (Graddol, 2006; Crystal, 2002). Indeed, David Crystal (2002) asserts that English has 
become such a pervasive power that it is now unstoppable, so that a shift to another language is unlikely in the near future. Because countries around the world have recognized the importance of English as a tool for acquiring knowledge and technology, they teach it at all educational levels and use it widely in their national life. In the words of Tuzlukova and Al-Mahrooqi (2010):

The importance of English cannot be underscored enough in any educational system that seeks to produce graduates who can compete in the international market and help in the development and advancement of their societies. ( $p$. 41).

Hence, effective oral and written communication in English tops the list of required employability skills in fields across any modern economy (Graddol, 2006; Ghasempoor, Liaghardar \& Jafari, 2011; Altbach, 2010). Requiring employees to possess a high level of language proficiency as well as cultural and pragmatic knowledge (Myles, 2009 ) is important because communicative ability involves more than mere knowledge of grammar and vocabulary. It involves the ability to express oneself clearly and appropriately depending on situation, interlocutors, topic, time, and place. For many employers, communication skills are more important than subjects studied during degree programs. Handling complex information and communicating it effectively is a major requirement in most professional fields (Wickramasinghe \& Perera, 2010).

\section{English in Oman}

Because English is the modern world's lingua franca, it is now playing a vital role in Oman. It is an essential instrument for the country's "integration into the rest of the world "and for the "Omanization" process, a government endeavor to replace expatriate workforce with nationals (Al-Mahrooqi \& Tuzlukova, 2010, p. 13).

Al-Issa (2007) holds that "Oman needs English - the only official foreign language in the country - as a fundamental tool for 'modernization', 'nationalization' and the acquisition of science and technology." (pp. 199-200). Currently, English is also important for the internationalization of the country's higher education system. In Altbach's (2010) opinion:

English is not only the preeminent language of science and scholarship in the $21^{\text {st }}$ century, but it is the language of engagement with the international academic community. Thus, SQU [Sultan Qaboos University] staff and students must be fluent in English. In most scientific fields, English is the primary language of knowledge dissemination, and the journals are in English. Even in the Middle East, where Arabic is widely spoken, English tends to be the key tool of academic discourse (p. 7).

In the Omani job market, a good command of English and a communicative ability certainly prove a competitive advantage (Al-Mahrooqi \& Tuzlukova, 2010; Al-Issa, 2007). Thus, Oman has invested heavily in teaching it at all levels, from grade one to undergraduate and postgraduate degrees (Al-Mahrooqi \& Asante, 2010). In fact, most Omani higher education institutions, public and private, teach all their science-based majors in English. They also teach many specializations in the humanities (e.g. education and the arts) in it. Unfortunately, this investment has not yet yielded expected gains. A majority of public school leavers lack the linguistic and communicative skills required for their future academic or professional success (Al-Mahrooqi \& Asante, 2010, Moody, 2009). Hence the majority entering higher education need an English foundation program (Al-Issa, 2011), which might last up to two years.

There are several reason for this. One is the curriculum, which does not do well in equipping students with communicative competence or performance. It is a top-down, centralized process, seeking to ensure that all students graduate with a range of information or knowledge deemed important by decision makers. (Al-Issa, 2011). Furthermore, teaching methodology remains firmly teacher-centered, despite repeated calls for communicative language teaching (Al-Balushi, 2001). These factors, coupled with an environment that uses English as a foreign language only, play a major role in producing students' low proficiency in the language and a lack of communicative ability. While previous research has speculated on such reasons, it has never addressed the issue directly. The aim of this study is, therefore, to tackle the issue directly, giving learners the opportunity to voice their opinions on how they were, or were not, taught communication skills at school and in higher education.

\section{The Study}

\subsection{The Design}

The research design is exploratory, aiming to investigate, from a student-perspective, the state of communication skills teaching in Oman. This type of design was thought appropriate since there is a dearth of research on this topic, and the present study is the first investigation on how communication skills are actually taught in Oman. Hence, it opens an uncharted line of investigation. Exploratory research provided qualitative data either through interviews, think-aloud protocols or written protocols. Written protocols were chosen over interviews because interviews require 
spontaneous answers, which might be hard for students whose English is weak. Written protocols allow students to think, write and rewrite their thoughts. Research has also found that students are able to structure their ideas more systematically when writing rather than speaking. To overcome the barrier of low English proficiency, students were given a chance to answer the questions in either Arabic or English.

\subsection{The Instrument}

Written protocols were obtained from students based on four written questions, which were:

1. How do you define English communication skills?

2. In your opinion, are English communication skills important in Oman? Please explain your answer.

3. How were you taught English communication skills at school?

4. How were you taught English communication skills at university?

The instrument also elicited background information about students' colleges, specialization, age, gender, and year of study in order to determine if any of these variables might make a specific difference to their answers to the questions.

Students were allowed to write in either English or Arabic, depending on which language they felt comfortable in using.

\subsection{The Participants}

Fifty-eight students from Sultan Qaboos University (SQU) answered the questions. In years ranging from the second to the fifth, they came from diverse colleges, including Arts and Social Sciences, Education, Agriculture, Engineering, and Commerce. There were 27 females and 31 males and their ages ranged from 19 to 23 . Twenty-five of the participants were English majors, and the rest studied their majors in English. Non-English majors went through a year of foundation English and studied two to three English for Specific Purposes (ESP) courses in their first and second year. Participants came from different regions in Oman, including Muscat, Dakiliyah, Dhahirah, Salalah, Sharqiyah, Batinah, and Wusta. All came from public schools which offered free education. Selection was based on their willingness to participate in the study.

\subsection{Data Analysis}

To arrive at a global understanding of the collected data, all responses to each question were read, similarities and differences identified and labeled, and then were grouped in separate tables for each question. Themes were identified and main points extracted for use in answering each question from the participants' collective point of view.

\subsection{The Results and Discussion}

To show the results clearly, the researcher displays each of the four questions and its answer.

\subsubsection{Defining English Communication Skills}

The written protocols reveal a lack of clarity regarding what communication skills involve. Some students defined them very generally, as in the following:

"the skills that a person used to communicate with people in order to understand him"

"they are the ways that each person have and use to communicate with others"

"it is the way in which people interact with each other", and

"the way that people tend to contact with each other".

Some students equated communication skills with speaking or the four language skills of reading, writing, listening and speaking. One participant defined them as "speaking and body language". Equating them with the four language skills, another participant wrote: "the output communicative skills are speaking and writing; the input communication skills are listening and speaking."

Some students confined communication to the familiar dichotomous definition of sender and receiver, stating that it is "the ability to send and receive messages". Expressed differently, for another participant it is "the ability to convey thoughts and receive feedback."

Others equated communication skills with language accuracy, with one participant saying that "they are the skills that enable people to contact with each other in accurate language." Still others associated them with "eye contact, phrases or other social methods" or "gesture, tone, and eye contact", or "things like when to pause and take turns and gestures", elements often emphasized by teachers in presentations and class discussions. Another participant 
equated them with proper vocabulary use and wrote: "the ability to choose good words that help you to interact with the other and how be a popular person in your society." Hence, word choice is thought to be a way of becoming popular in a certain context and is defined as a good communication skill, which is not far from the truth.

Nine participants arrived at definitions that were more elaborate, mentioning successfully communicating with people of the opposite gender, possessing different styles from different countries and in different situations. One mentioned the necessity of being polite, while another added that it is the ability to deal with or solve social problems. While this last definition involves communication at its core it rather goes beyond it.

None of the definitions was wrong, but 49 defined communication skills in a very limited sense, and only nine thought about communication as being associated with the context and the kind of people one is in communication with. The majority's unawareness of the different dimensions of communication could arise from a deficient curriculum which fails to address this vital component, as was indicated by Al-Issa (2007).

\subsubsection{The Importance of English Communication Skills in Oman}

Without exception, all participants expressed their agreement, some stating that English communication skills are very important or vital.

Students' explanations of their positive opinion of the importance of English communication skills reveal a deeper understanding of what communication entails than was revealed in their definitions. The fact that "importance" was linked to communication skills made respondents think about different situations and contexts where English could be used. They have a keen awareness of the international status of English and the fact that it is used in the Omani context and is a requirement for success in education and employment. They also believe that being able to communicate in English reflects their linguistic competence, equips them with confidence, earns them respect, and saves them from being misunderstood; or even being considered rude or impolite when they fall back on their first language and translate Arabic expressions which are appropriate in their native culture but unacceptable in English (Umale, 2011). A few participants mentioned that being able to communicate in English might help solve social problems, resolve conflicts, and gain more friends. One participant equated communication (part of which is communication in English) with existence. A number considered English the door to new horizons of knowledge and opportunity. Hence English communication skills are viewed as having positive effects on one's personality, education, future opportunities, integration with the world, interaction with speakers of other languages, and social relationships.

\subsubsection{English Communication Skills at School}

Only 14 of the 58 participants mentioned that they were indirectly taught communication skills at school through speaking in class (conversation), group work, debates, discussions, presenting ideas, stories, and listening to teacher experiences. One mentioned reading written dialogues and then mimicking them. Another mentioned listening to dialogues and then mimicking them. Some were taught a few expressions to enable them to start a conversation, thank someone, apologize, and how to address teachers and mothers [parents]. In the words of one participant, "I was taught some simple communication skills. For example, how to deal with teachers and the way to speak to mothers. Indeed they did not teach us how to communicate with different people."

Forty-four participants said they were not taught communication skills in class, although one emphasized that the school stressed the importance of addressing teachers and the principal politely. However, much of the instruction on politeness which some received was in Arabic. Many participants indicated that their school taught grammar rules as pre-cursors for acquiring communicative ability, which was expected to emerge eventually without the need for any direct instruction. To illustrate, one participant stated: "In school I learned grammar only. But as you can notice it is not that good - my grammar." As research has found, teaching English grammar does not necessarily improve learners' communication skills (Tubtimtong, 1999). Some teachers taught English in Arabic and explained everything in Arabic. Hence, students graduated without much competence in English. One participant wrote: "I did not learn communication skills in English because I did not learn English from schools. I learnt it from institutes because the teachers who taught me neither taught me communication skills nor English itself". Another participant stated: "Unfortunately, there wasn't much on spoken English communication skills. Thus, I feel I learnt almost nothing regarding this. About written English communication skills, we were taught how to write formal and informal letters, but writing letters isn't applicable in my life till now. Teaching us how to write formal emails maybe more beneficial." Many of the 44 participants who said they were not taught communication skills at school stated that whatever they had learnt in terms of communicative ability came mostly from extramural interaction in school English clubs, private language institutes, interaction with friends, and family members who went to private schools or had better English than they. It is unfortunate that the majority of the participants stated that English communication was not part of their learning experience in public school English classrooms. 
According to Tubtimtong (1993), students need to actively use the language to give them confidence and to feel its communicative value, something painfully missing in the Omani public school curriculum as the answers to the above question have shown. This is also in line with Al-Issa's (2011) and Al-Balushi's (2001) assertions that neither the curriculum nor the methodology used in the Omani English classroom is effective enough to foster students' communicative competence and performance.

\subsubsection{English Communication Skills at the University}

The majority of students stated that they were not taught communication skills indirectly at university either. English Education and English Arts students (25 in number) stated that their two speaking courses, in addition to linguistics courses, did teach them some communication skills. However, these were inadequate in the opinion of most of the 25 English majors. One of them wrote:

I was taught communication skills almost through linguistic courses as well as speaking courses. In some of these courses, we are asked to do presentations in which we learn more how to communicate with others. However, still there is something missing that I think we need to have more courses that only focus on teaching communication.

Another echoed the same opinion, saying:

Communication skills were not taught even at the university. I am a graduating student and I feel like I don't have English communication skills as I should. We were given many speaking and writing courses. Speaking courses are not enough as I have always believed. We weren't given situations that are fully related to our real life.

Other students mentioned they were taught the rules of accurate language in grammar classes. While teaching the rules is essential, Widdowson (1978) stresses that it has to go hand in hand with explicit instruction on pragmatic use.

One English major mentioned the Experiential Learning Program, which she enrolled in when she was a student at SQU's Language Centre. She stated that that program, which assigns a limited number of students to work as teacher assistants in an English medium private school for one day a week throughout a semester, helped her gain some communicative competence, as she had to use the language in a real context. This again supports Tubtimtong's (1999) assertion that college-level students of English as a foreign language need courses that promote their active and confident participation in genuine situations. Although the Experiential Learning Program seems to be beneficial for the development of students' communication skills, it is offered to around 18 English majors only, out of 140 students, because the number of cooperating private schools is limited, and not all private schools want to take on novice Omani students as teacher assistants. Perhaps one reason for this reluctance is that these students go to the schools while they are still in year one of their credit courses and hence possess limited English, which jeopardizes their interaction with the English-speaking teachers and students. Perhaps this program could be postponed to later years of study and participation made possible for all English majors.

Students from specializations other than English stated that they learnt whatever communication skills they have indirectly through interaction with peers, professors, group work, presentations debates, and participation in the English and Translation Society (ETS) - a student-run university-wide club that offers workshops on drama, creative writing, speaking and grammar, and Omani literature. While it is advantageous to have such opportunities, it is essential to dedicate a course to the explicit teaching of communication skills, especially in areas related to pragmatics, which deals with teaching speech acts that reflect the conventions and rules acceptable by the target language (Jiang, 2006). Kasper and Schmidt (1996) suggest that learners need explicit instruction in pragmatic competence to achieve communicative ability. Canagarajah (2006) cautions against overly focusing on grammar instruction at the expense of proficiency in pragmatics.

In fact, research has shown that training students in using different speech acts and language functions, such as introducing oneself, apologizing, requesting, congratulating, complementing, disagreeing, and interrupting, has resulted in short and long-term gains in terms of students' communicative competence and performance (Kasper, 1997; Rose \& Kasper, 2001; Kondo, 2001).

\section{Conclusion and Implications}

The study set out to investigate the status of communication skills teaching in Omani public schools and at Sultan Qaboos University. Findings indicate that, for the most part, communication skills are not directly addressed. Most students learned them through personal interaction with family members, friends, teachers (inside and outside the classroom), private institutes, and English clubs. English majors benefited from the Language Centre's Experiential Learning Program and the two speaking courses they took as a requirement in the Department of English. They also benefited from grammar and linguistics courses, which they felt taught them rules for using English accurately. There were, however, no English communication skills courses per se, nor segments of courses devoted to 
communication and pragmatics. Hence, most students felt that their communication skills were very poor. Even students on the verge of graduation expressed this, with much regret and sorrow.

The study thus highlights the importance of integrating communication skills into the school and university curriculum. This is made the more vital by the fact that English is not spoken as a native language in Oman. Hence, teachers have to deal with communication skills explicitly in the classroom. Research has found explicit instruction effective in teaching pragmatic skills, which are an indispensible component of communicative ability (Kasper, 1997; Rose \& Kasper, 2001; Kondo, 2001). Curricula must involve students actively in their studies and in genuine communicative tasks. Scenarios involving different speech acts, sketches, drama, debates, creative storytelling, data collection from real life, interactive video or film viewing, creating conversations and role-play, and using literature circles are all activities that encourage students to speak and use the language. If explicit instruction on pragmatics is added to these activities - strongly emphasizing rules for the appropriate use of language - this will, as research has shown, definitely produce positive results. However, since most teachers are not well-trained to integrate communication skills, the Ministry of Education, colleges and universities need to provide professional development courses to demonstrate to teachers how this can be done. Because the 58 participants in the present study came from different regions in Oman, the results can be safely generalized to all public school graduates. However, the participants came from only one university. Hence, an investigation is needed to compare curricula and teaching methods across higher education institutions to determine if communication is taught elsewhere in the tertiary sector. Future research could also address communication skills from many perspectives. For example, a study could investigate classroom discourse and types of instructional interaction that take place inside the classroom. This would reveal how much Arabic is used in instruction, patterns of student and teacher talk, whom interaction involves, and whether it is teacher-driven, teacher-centered, or student-centered.

\section{References}

Al-Balushi, R. (2001). ELT in the Sultanate of Oman. RELO Newsletter, 5, 5-6.

Al-Issa, A. (2007). The implications of implementing a 'flexible' syllabus for ESL policy in the Sultanate of Oman. RELC, 38(1), 199-215.

Al-Mahrooqi, R., \& Tuzlukova, V. (2010). Introduction: Cultural perspectives and ELT in Oman. In R. Al-Mahrooqi \& V. Tuzlukova (Eds.), The Omani ELT Symphony: Maintaining Linguistic and Socio-cultural Equilibrium (pp. 13-29). Muscat: Sultan Qaboos University Academic Publication Board.

Al-Shaqsi, H. (2012). Unemployment in Oman. Muscat Daily. Wednesday, January 11, 2012.

Altbach, P. (2010). Notes on the future of SQU: Comparative perspectives. In Towards a Long-term Strategic Plan for Sultan Qaboos University: Proceedings of the International workshop (9-10 November 2010), pp. 3-9. Muscat: Sultan Qaboos University Press.

Bisong, J. (1995). Language choice and cultural imperialism. ELT Journal, 49(2), pp. 129-132.

Canagarajah, S. (2006). Changing communicative needs, revised assessment objectives: Testing English as an international language. Language Assessment Quarterly, 3(3), pp. 229-242.

Crystal, D. (1992). An Encyclopedic Dictionary of Language and Languages. Oxford: Blackwell Publishers.

Crystal, D. (2002). English in the New World. Babylonia, 1, 16-17.

Friedman, G. (2009). The Next 100 Years: A Forecast for the $21^{\text {st }}$ Century. New York: Anchor Books.

Ghasempoor, A., Liaghardar, \& Jafari, E. (2011). The internationalization of higher education: An effective approach for Iran's higher education. Higher Education Studies, 1(2), 35-40.

Graddol, D. (2006). English Next: Why global English may mean the end of "English as a foreign language". London: The British Council. [Online] Available: http://www.britishcouncil.org/learning-research-english-next.pdf (January 12012 )

Issan, S., Gomaa, N. (2010). Post Basic Education Reforms in Oman: A case study. Literacy Information and Computer Education Journal (LICEJ), 1(1), 19-27.

Jiang, X. (2006). Suggestions: What should ESL students know? System, 34, 36-54. [Online] Available: http://krpb.pbworks.com/f/suggest\%2BJiang_Xiangying.pdf (January 1, 2012)

Kasper, G. (1997). Can pragmatic competence be taught? [Online] Available: http://www.ll1.hawaii.edu/nflrc/Networks/NW6 (January 1, 2012)

Kasper, G., \& Schmidt, R. (1996). Developmental issues in interlanguage pragmatics. Studies in Second Language 
Acquisition, 18, 149-169.

Kondo, S. (2011). Instructional effects on pragmatic development: Refusal by Japanese EFL learners. Publications of Akenohoshi Women's Junior College, 19, 33-51.

Mazawi, A. (2010). Knowledge, academic work and governance: Implications for a sustainable development of higher education in the GCC region. In Towards a Long-term Strategic Plan for Sultan Qaboos University: Proceedings of the International Workshop (9-10 November 2010), pp. 41-55. Muscat: Sultan Qaboos University Press.

Moody, J. (2009). A neglected aspect of ELT in the Arabian Gulf: Who is communication between? In Zhang, L. J., R. Rubdy, \& Alsagoff, L. (Eds.), Englishes and Literatures-in-English in a Globalized World: Proceedings of the 13th International Conference on English in Southeast Asia (pp. 99-119). Singapore: National Institute of Education, Nanyang Technological University.

Myles, J. (2009). Oral competency of ESL technical students in workplace internships. TESOL-EJ, 13(1). [Online] Available: http://www.tesl-ej.org/wordpress/issues/volume13/ej49/ej49a2/ (January 1, 2012)

Phillipson, R. (1992). Linguistic Imperialism. Oxford: Oxford University Press.

Rose, K., \& Kasper, G. (2001). Pragmatics in Language Teaching. Cambridge: Cambridge University Press.

Tubtimtong, W. (1993). The problem of translating communicative needs into course design and implementation. Paper presented at the SEAMED Regional Language Centre Regional Seminar (Singapore, April 19-21, 1993).

Tuzlukova, V., \& Al-Mahrooqi, R. (2010). Culture-based curriculum dimensions. In R. Al-Mahrooqi \& V. Tuzlukova (Eds.), The Omani ELT Symphony: Maintaining Linguistic and Socio-cultural Equilibrium (pp. 33-70). Muscat: Sultan Qaboos University Academic Publication Board.

Umale, J. (2011). Pragmatic failure in refusal strategies: British versus Omani interlocutors. Arab World English Journal, 2(1), pp.18-46. [Online] Available: www.awej.org (January 1, 2012)

Wickramasinghe, V., \& Perera, L. (2010). Graduates', university lecturers' and employers' perceptions towards employability skills. Education and Training, 52(3), 226-244. [Online] Available: www.emeralinsight.com/0040-0912.htm (January 1, 2012)

Widdowson, H. (1978). National-functional syllabus. In C. Blatchford \& J. Schacter (Eds.), One TESOL'78 (pp. 32-35). Washington DC: TESOL Press. 